\title{
RESEARCH IN CENTRIFUGAL ROTARY GRINDER OF FORAGE GRAIN
}

\author{
Peter Savinyh $^{1}$, Alexey Isupov ${ }^{1}$, Ilya Ivanov ${ }^{2}$, Semjons Ivanovs ${ }^{3}$ \\ ${ }^{1}$ North-East Agricultural Research Institute, Russia; ${ }^{2}$ Vologda State Dairy Academy, Russia; \\ ${ }^{3}$ Latvia University of Life Sciences and Technologies, Latvia \\ semjons@apollo.lv
}

\begin{abstract}
One of the most promising tools for grinding grain materials in recent years are centrifugal rotary grinders for forage grain with a knife working tool. A combination of grinding by cutting and chipping with feeding the crushed material to the cutting pairs due to inertial forces, and not due to pneumatic transport, can significantly reduce the specific energy consumption in comparison with the most common grinders - hammer crushers, which use impact for grinding. The object of the research is the design of a centrifugal rotor grinder with one movable lower disc with contractors installed on it, with two degrees of grinding, and a separating surface, consisting of straight wedge-shaped knives. The research of the operation of the centrifugal rotary grinder was carried out on a laboratory sample using the method of planning a multifactor experiment, in particular, the plan of the Box-Benkin experiment. The mathematical models obtained from the experimental data made it possible to describe the ongoing processes with an accuracy of more than $95 \%$ and to establish the influence of factors and their interactions for each selected optimisation criterion, as well as to obtain information for understanding the ongoing physical processes.
\end{abstract}

Keywords: grinding, knives, efficiency, energy consumption.

\section{Introduction}

The grain processing products are the most important source of nutrition for pigs, chickens and other animals $[1 ; 2]$. According to statistical data more than half of all the costs of livestock production are the costs associated with the production of forage [3]. Moreover, only a quarter of all the energy contained in the forage is returned in the form of meat, milk, etc. But the remaining share is spent on maintaining the viability of the animal body - the processes of respiration, blood circulation, etc. Therefore, reducing the cost of forage; increasing its nutritional value and assimilation by the animal body are the key goals of animal husbandry.

The studies of many scientists are devoted to the research of grinding grain with various types of hammer crushers $[2 ; 4]$. Special importance in these studies is devoted to the research of energy consumption of the grinding process. There is great interest for practice and science in the means for crushing feed grain, operating in the border area that is combining the process of crushing by shear and chipping [5-9]. This is due to the fact that grinding with a knife working tool allows to achieve minimal energy consumption in comparison with other grinding methods, and especially with the most common - hammer crushers, which use impact for grinding (up to $54 \mathrm{MJ} \cdot \mathrm{t}^{-1}$ ) [6;9-11]. In comparison with impact the use of cutting and shearing can also significantly reduce the content of the dust-like fraction (the fine fraction with medium and fine grinding is up to $30 \%$ ) in the finished product.

Many authors also attribute to significant disadvantages of hammer crushers [12-15], rapid wear of the working tools, relatively high metal consumption (up to $500 \mathrm{~kg} \cdot \mathrm{h} \cdot \mathrm{t}^{-1}$ ), but at the same time point to the simplicity of the design and fairly high reliability.

A significant disadvantage of the grinders with a knife working tool is also dependence of the quality of the resulting product, efficiency and energy consumption of the grinder upon the condition of the cutting element of the grinder.

Therefore, the reliability and longevity of the cutting element in such grinders are the main limiting factors for its widespread adoption. One of the solutions of the indicated problem may be to reduce the sharpness of the knife blade by changing its angle of attack.

The purpose of this research is to establish the impact of the angle of attack of the wedge-shaped knives, the frequency of rotation and supply of the grain material upon the technological and quality indicators of the centrifugal rotary grinder.

\section{Materials and methods}

Experimental studies were carried out using the developed methods and existing methods for conducting a multifactor experiment and state standards, statistical methods for processing the research 
results, standard and developed experimental equipment [16-19]. As an object of the research there was used a centrifugal rotary grinder of forage grain, shown in Figure 1a. (Patent RU 2656619) [12].

The shredder operates as follows: the crushed material first enters the distribution bowl (accelerator), where, under the action of centrifugal forces of inertia, it is evenly distributed along its entire perimeter, thereby ensuring stable supply of the crushed material to the first and the second grinding stages, which are a cutting pair consisting of a stationary upper disc with evenly installed wedge-shaped knives (Fig.1b) and a counter-knife (Fig. 1c) rotating together with the lower disc. After crushing in the second stage the crushed material moves under the action of the centrifugal inertial forces to the separating surface, which is a series of fixed wedge-shaped knives, installed in such a way that the adjacent knives have the ability to overlap each other. Later on, the sorted crushed material, under the action of centrifugal forces of inertia and the air flow created by rotating counterparts, is removed from the working chamber into the outlet pipe.

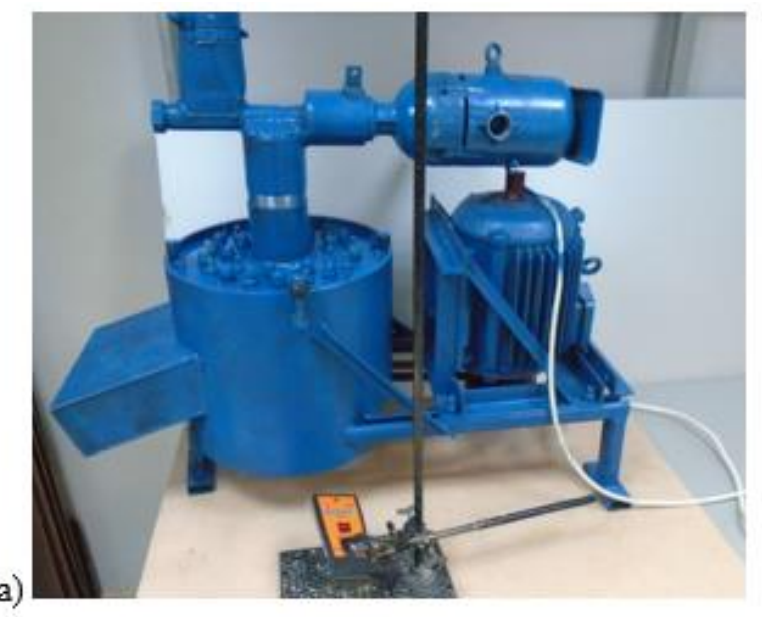

b)

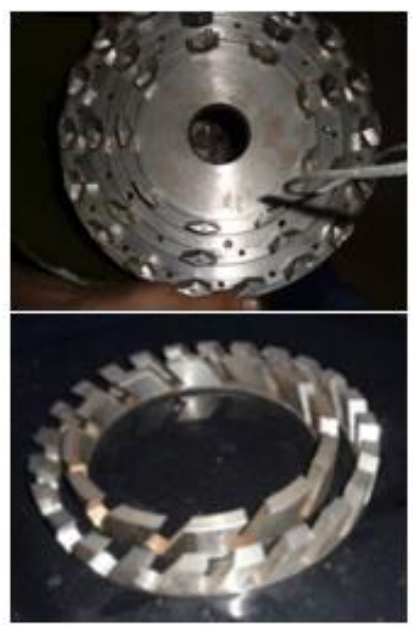

Fig. 1. Laboratory installation of the rotary-centrifugal grain grinder (a), rings with counterknives (b) lower disc with knives (c)

To achieve this goal, the method of planning a multifactor experiment was used [16-19], namely, the Box-Benkin plan for three factors (Table 1). The factors and their interactions were assessed according to the optimisation criteria: the amount of power consumption (energy consumption for the grinding process) $y_{1}$, the grinder productivity $y_{2}$, as well as the percentage of particles more than $3 \mathrm{~mm}$ $y_{3}$ in grinding and the percentage of dusty fraction in grinding $y_{4}$.

Based on the results of earlier investigations, the following settings were made on the grinder: the gap of the separating surface $-2.5 \mathrm{~mm}$; the number of knives at the first and the second stages of grinding was 9 and 18 pcs., respectively.

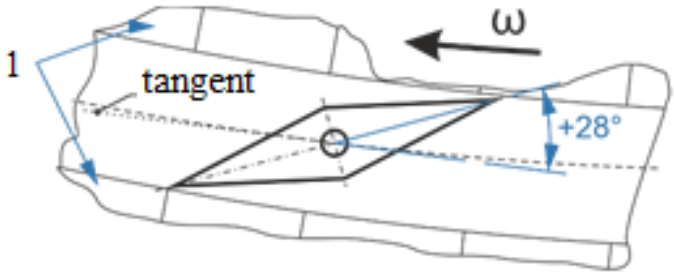

a)

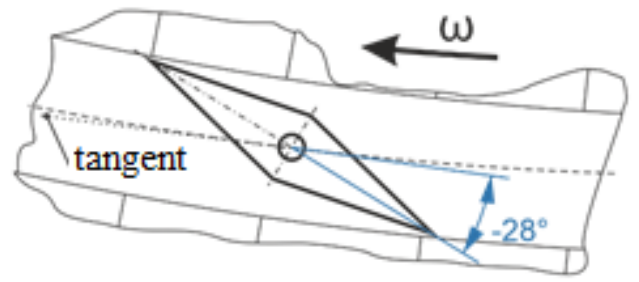

c)

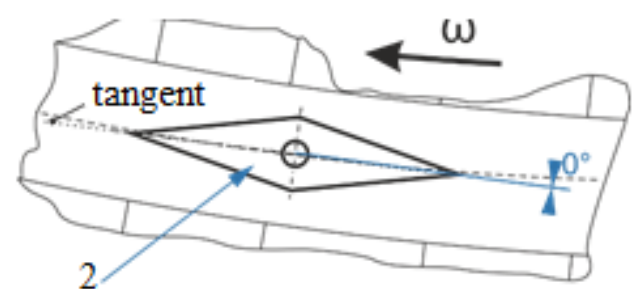

b)

1 - counter-knives of the lower disc

2- wedge-shaped knife

Fig. 2. Positive (a), zero (b) and negative (c) angle of attack of the wedge-shaped knives 
Factors and levels of their variation

Table 1

\begin{tabular}{|c|c|c|c|c|}
\hline \multirow{2}{*}{ Name and dimension } & Conventional & \multicolumn{3}{|c|}{ Levels of factor } \\
\cline { 3 - 5 } & sign & -1.0 & 0 & +1.0 \\
\hline Grain supply, $\mathrm{kg} \mathrm{s}^{-1}$ & $x_{1}$ & $1.36(30)$ & $2.29(60)$ & $3.03(90)$ \\
\hline $\begin{array}{c}\text { Rotation frequency of the } \\
\text { rotor, s }\end{array}$ & $x_{2}$ & 800 & 1000 & 1200 \\
\hline $\begin{array}{c}\text { Angle of attack of the } \\
\text { wedge-shaped knife, deg. }\end{array}$ & $x_{8}$ & -28 & 0 & +28 \\
\hline
\end{tabular}

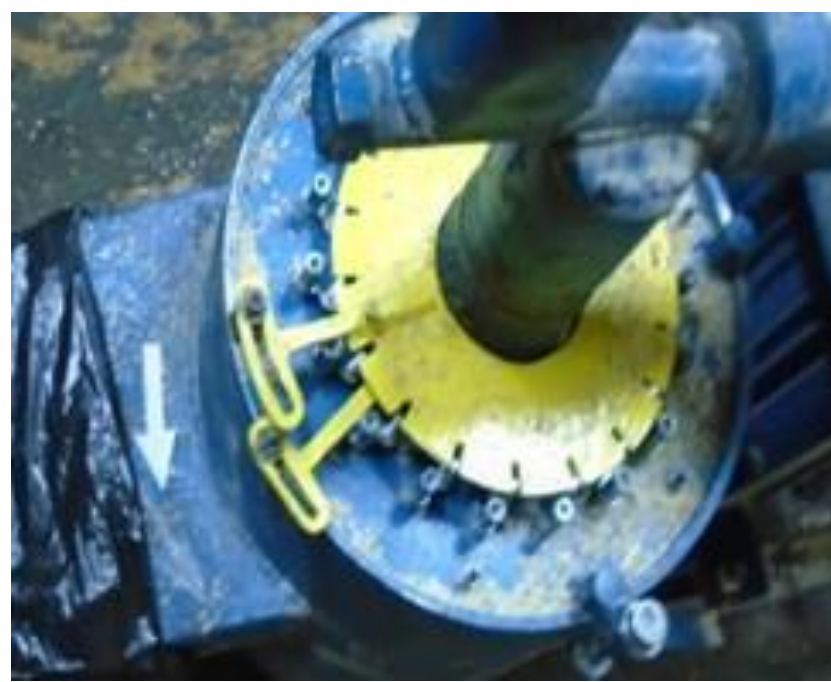

Fig. 3. Mechanism of synchronous rotation of knives

The values of the measured parameters were produced in accordance with the test standard, using serial measuring equipment. The accuracy of the experimental data is confirmed by the rather high accuracy of the measuring instruments and equipment used in the research: to determine the performance of the grinder, the VP-50 scales were used with an accuracy of $0.5 \mathrm{~g}$, the weighed portions and the remainder on the sieves were weighed on the NGY-300 electronic scales with accuracy to $0.01 \mathrm{~g}$; measurement and recording of the power consumption indicators was carried out using a Mercury 221 electric energy meter connected to a PC via the USB interface in CAN/RS-232/RS485, and the instantaneous values were controlled by the K-505 measuring complex.

\section{Results and discussion}

As a result of statistical processing of the experimental data, adequate mathematical models (1), (2), (3) and (4) were obtained, which describe the processes occurring within the selected range of variation of factors, with a reliability of at least $95 \%$.

$$
\begin{gathered}
y_{1}=8.04+0.335 x_{8}+0.94 x_{1}+0.375 x_{2}+0.305 x_{8} x_{1}+0.255 x_{8} x_{2}-0.315 x_{1} x_{2}- \\
-0.527 x_{8}^{2}-0.677 x_{1}^{2}+0.242 x_{2}^{2}, \\
y_{2}=0.948+0.159 x_{8}-0.047 x_{1}-0.054 x_{2}- \\
-0.377 x_{8} x_{2}+0.047 x_{1} x_{2}+0.377 x_{8}^{2}+0.094 x_{2}^{2}, \\
y_{3}=1.5+1.59 x_{8}+0.36 x_{1}+0.42 x_{8}^{2}+1.13 x_{8} x_{2}-0.42 x_{1}^{2}+0.55 x_{2}^{2}, \\
y_{4}=5.86-2.07 x_{8}+1.25 x_{1}+0.77 x_{2}+0.99 x_{8}^{2}+1.4 x_{8} x_{1}-1.75 x_{8} x_{2}+1.05 x_{1} x_{2} .
\end{gathered}
$$

The quality of the resulting product is most influenced by the angle of attack of the knives, the increase in the angle of attack of the knives in the positive direction $\left(x_{8}>0\right)$ contributing to the growth of particles over $3 \mathrm{~mm} y_{3}$ and a decrease in the amount of the dust-like fraction $y_{4}$;

The angle of attack of the wedge-shaped knives $x_{8}$ is the most significant factor in determining the productivity of the grinder $y_{2}$, and the use of "negative" angles of attack of the knives $\left(x_{8}<0\right)$ leads to a 
drop in the productivity of $y_{2}$ and vice versa, with a positive angle of attack $\left(x_{8}>0\right)$, the productivity of the grinder $y_{2}$ increases.

The amount of the power consumed by the grinder $y_{1}$ is most influenced by the supply of the grain material $x_{1}$ and the angle of attack of the wedge-shaped knives $x_{8}$, and, when they increase, they do not lead to a significant leap in the power consumption $y_{1}$, while their decrease will reduce the energy consumption $y_{1}$ not less than by a quarter.

The rotation frequency of the rotor of the grinder $x_{2}$ is the least significant factor for changing the energy consumption of the forage grain chopper $y_{1}$ and does not have such a high impact on the quality of the resulting product $y_{3}$ and $y_{4}$, in contrast to the angle of attack of the wedge-shaped knives $x_{8}$ and the delivery of the grain material $x_{1}$, but this factor is the second most important to change the shredder performance $y_{2}$. At the same time, an increase in the angle of attack of the wedge-shaped knives $x_{8}$ with a simultaneous decrease in the rotational frequency $x_{2}$ leads to intense increase in the productivity of the grinder $y_{2}$ in comparison with the negative angle of attack of the wedge-shaped knives $x_{8}=-1.0$ with a simultaneous increase in the rotation frequency of the rotor $x_{2}$. At a zero angle of attack of the knives $x_{8}=0.0$, the power consumed by the grinder $y_{1}$ approaches the maximum values while having minimum productivity $y_{2}$.

The analysis of the interactions of factors in mathematical models (1), (2), (3) and (4) is carried out using two-dimensional sections (Fig. 4), which shows that on the graph of the angle of attack of wedgeshaped knives $\mathrm{x} 8$ versus the speed $\mathrm{x}_{2}$ at maximum feed grain material $x_{1}=1$ (Fig. 4 , a) a decrease in the angle of attack of wedge-shaped knives $x_{8}$ leads to a decrease in energy consumption y1, regardless of the speed $\mathrm{x}_{2}$. But on the graph of dependence of the angle of attack of the wedge-shaped knives $x_{8}$ on the rotation frequency $x_{1}$ at maximum delivery of the grain material $x_{2}=1.0$ (Fig. 4, b), showing the change in the content of the dust-like fraction $y_{4}$ and the content of particles with a size of more than $3 \mathrm{~mm} y_{3}$, it is evident that increase in the rotation frequency of the rotor $x_{1}$ of the grinder, when setting negative angles of attack of the wedge-shaped knives $x_{8}<0$, leads to an increase in the dust-like fraction $y_{4}$ from 5 to $12 \%$ and a decrease in the content of particles with a size of more than $3 \mathrm{~mm} y_{3}$ from 2 to $0 \%$. Increasing the positive angle of attack of the wedge-shaped knives $x_{8}>0$ and the rotation frequency of the rotor $x_{2}$ of the grinder, the content in the grinding of the pulverised fraction $y_{4}$ decreases from 5$9 \%$ to $7-8 \%$, and the content of the particles larger than $3 \mathrm{~mm} y_{3}$ increases from 1.5-2\% up to $2.5-5 \%$.

From the graph of the angle of attack of the wedge-shaped knives $x_{8}$ and the delivery of the grain material $x_{1}$ at the maximum rotation frequency of the rotor $x_{2}=1.0$ of the grinder (Fig.4, c), it is evident that at the angle of attack $x_{8}=0.74$ and feed $x_{1}=0.627$ the power, consumed by the grinder, is maximum, and it is $y_{1}=9.07 \mathrm{~kW}$. In addition, the movement towards negative angles of attack $x_{8}<0$ and a decrease in delivery $x_{1}$ makes it possible to achieve energy consumption less than $y_{1}=7 \mathrm{~kW}$, but this entails an increase in the fraction of the dusty fraction $y_{4}$ to $10.55 \%$. At the same time, with an increase in the positive angle of attack $x_{8}>0$ of the knives and a decrease in the delivery of the grain material $x_{1}$, the energy consumption is achieved at $y_{1}=7.11 \mathrm{~kW}$, and the content of the dust fraction in the grinding is $y_{4}=0.1 \%$. From the graph of the rotational frequency $x_{2}$ and the delivery of the grain material $x_{1}$ at the maximum positive angle of attack $x_{8}=1.0$ of the wedge-shaped knives (Fig.4, d) it is evident that an increase in the rotation frequency $x_{2}$ leads to a proportional increase in the dusty fraction $y_{4}$, and this growth increases with an increase in the delivery $x_{1}$ of the grain material. So, for example, the content of the dusty fraction $y_{4}$ in the grinding at a minimum rotation frequency $x_{2}$ varies from 4.15 to $7.35 \%$, and at a maximum rotation frequency $x_{2}$ from 0.1 to $7.5 \%$. In addition, power $y_{1}$, consumed by the grinder, increases by almost 1.7 times with an increase in the frequency $x_{2}$ and the delivery of the grain material $x_{1}$, and it amounts to $8.97 \mathrm{~kW}$. But in the same graph of the rotation frequency $x_{2}$ and the delivery of the grain material, yet at the maximum negative angle of attack $x_{8}=-1.0$ of the wedge-shaped knives (Figure 4, e), it is noted that the growth of the dust-like fraction $y_{4}$ is proportional to the growth in the delivery of the grain material $x_{1}$, and at the maximum rotation frequency $x_{2}$ the interval is from 5.2 to $12.35 \%$, and at the minimum rotation frequency $x_{2}$ from 7.6 to $10.55 \%$. At the rotation frequency $x_{2}$ from -0.2 to 1 , the power consumption $y_{1}$ of the grinder smoothly changes from 7 to $7.6 \mathrm{~kW}$, while the maximum values at the maximum and minimum delivery $x_{1}$ of the grain material; however, at the frequency of $x_{2}$ from - 1 to -0.2 it has a "steeper" character, changing in proportion to the speed $x_{2}$ within the range from 7.45 to $5.67 \mathrm{~kW}$. 

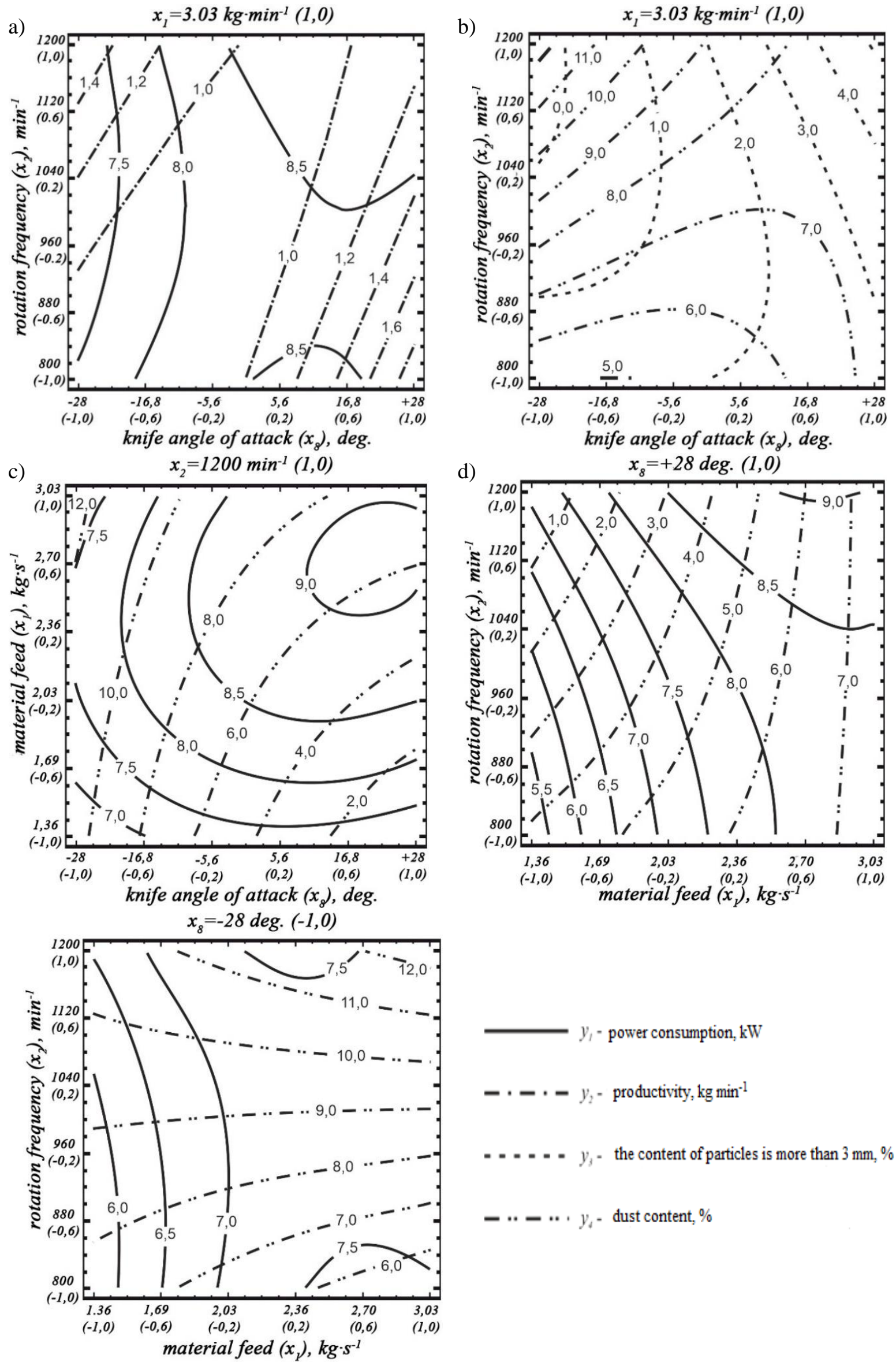

Fig. 4. Graphs of two-dimensional response surfaces 
It follows from the analysis of the graphs of the two-dimensional sections and coefficients in the equations of the mathematical models that an increase in the rotation frequency leads to a directly proportional increase in the energy consumption; and, at the same time, an increase in the rotation frequency causes an increase in the centrifugal force of inertia, which makes it possible to reduce the time for moving the crushed material to the degrees of grinding and separating surface. But this also leads to an increase in the number of contacts between the pair of the cutting knife-counter knife and the grain, which leads to a decrease in the content of the coarse fraction and the growth of the fine one.

The change in the angle of attack changes the conditions of the destruction process; for example, at a negative angle of attack of the wedge-shaped knives, there is observed a maximum content of the dusty fraction and the minimum content of particles with a size of more than $3 \mathrm{~mm}$, which may point to an increased effect of the impact destruction of the kernels in comparison with grinding by the method of cutting and chipping; while at a positive angle of attack, the content changes; depending on the angle of attack of the knives; the conditions for the movement of the grain material change, which affects the performance of the grinder. For example, at a negative angle of attack, the grinded grain material, due to the Coriolis force of inertia directed in the opposite direction from the direction of rotation of the rotating lower disk, falls into the "pocket", formed by the plane of the knife and the outer plane of the counter knives, thereby reducing the performance of the grinder. In a subsequent work in this direction, it is necessary to investigate the option with a positive angle of attack of the knives, since it provides the best quality of the finished product with a sufficiently high performance of the grinder, as well as the possibility of reducing the power consumption while maintaining the quality of the finished product.

\section{Conclusions}

1. The delivery of the grain material to the grinder plays the key role for the criteria of the content in grinding of particles of more than $3 \mathrm{~mm}$ and the dust-like fraction, as well as the power consumed by the grinder, which can be explained by a change in the course of the grinding process in the working area (destruction by cutting and chipping or impact) and an increase in the inertia torque of the rotating lower disc due to an increase in its mass because of the grain on its surface.

2. The angle of attack of the wedge-shaped knives is the most important factor for all the selected optimisation criteria. At a zero angle of attack of the wedge-shaped knives, on the whole, the "local resistance" increases and is $52.8 \%$ for the first row and $81.4 \%$ for the second row of knives, and at an angle of attack of $\pm 28^{\circ}$ these values are respectively $47.05 \%$ and $72.15 \%$.

\section{References}

[1] Сысуев В.А., Алешкин А.В., Савиных П.А. Кормоприготовительные машины. Теория, разработка, эксперимент. (Forage machines. Theory, development, experiment). Киров, 2008. $640 \mathrm{p}$.

[2] Sysuev V., Ivanovs S., Savinyh P., Kazakov V. Movement and transformation of grain in two-stage crusher. Engineering for Rural Development, Proceedings, Vol.14, 2015, pp. 22-27.

[3] Скоркин В. Современные требования производства конкурентоспособной молочной продукции (Contemporary requirements for the production of competitive dairy products). Вестник ВНИИМЖ (Vestnik VNIIMZh), No. 4 (28), 2017. pp. 4-9.

[4] Bulgakov V., Holovach I., Bandura V., Ivanovs S. A theoretical research of the grain milling technological process for roller mills with two degrees of freedom. INMATEH - Agricultural Engineering. Vol. 52(2), 2017, pp. 99-106;

[5] Heinrichs A.J., Buckmaster D.R., Hevko R.B., Liubin M.V., Tokarchuk O.A., Lyashuk O.L., Pohrishchuk B.V., Klendii O.M. Determination of the parameters of transporting and mixing feed mixtures along the curvilinear paths of tubular conveyors. INMATEH - Agricultural Engineering, Volume 55, Issue 2, 2018. pp. 97-104.

[6] Marczuk A., Caban J., Aleshkin A.V., Savinykh, P.A., Isupov A.Y., Ivanov I.I. Modeling and simulation of particle motion in the operation area of a centrifugal rotary chopper machine. Sustainability. Vol 11 (18), 2019, art.4873.

[7] Marczuk A., Blicharz-Kania A., Savinykh P.A., Palichyn A.V., Ivanov I.I. Studies of a RotaryCentrifugal Grain Grinder Using a Multifactorial Experimental Design Method. Sustainability. Vol. 11 (19), 2019, art. 5362. 
[8] Солнцев Р.В. Центробежный измельчитель зерна. Вестник Алтайского аграрного университета, выпуск (Centrifugal grinder of grain. Bulletin of the Altai Agrarian University), Vol.4 (66), 2010, pp. 76-80.

[9] Дружинин Р.А. Совершенствование рабочего процесса ударно-центробежного измельчителя (Improvement of the working process of the impact-centrifugal grinder). Воронеж, 2014. $169 \mathrm{p}$.

[10] Иванов В. Совершенствование режимов работы дискового измельчителя кормового зерна (Improvement of operating modes of a disk grinder of fodder grain). Зерноград, 2014, 132 p.

[11] Миронов К.Е. Повышение эффективности процесса измельчения зерна с обоснованием параметров рабочих органов дробилки ударно-отражательного действия: (Increasing the efficiency of the process of grinding grain with the substantiation of the parameters of the working bodies of the shock-reflective crusher). Княгинино, 2018. $142 \mathrm{p}$.

[12] Савиных П.А., Саитов В.Е., Сухляев В.А., Иванов И.И., Палицын А.В., Кузнецов Н.Н. Устройство для измельчения сыпучих материалов (Device for crushing bulk materials). Патент России No RU 2656619, 2018.

[13] Солнцев P.В. Центробежный измельчитель зерна. Вестник Алтайского аграрного университета (Centrifugal grinder of grain. Bulletin of the Altai Agrarian University), No 4 (66), 2010, pp.76-80.

[14]Фомин В.В. Снижение энергоемкости и повышение однородности измельчения зерна в малогабаритном центробежно-роторном измельчителе. (Reducing energy consumption and increasing the uniformity of grinding grain in a small-sized rotary centrifugal grinder). Новосибирск, 2010, 23 p.

[15] Bavram M., Oner M. Bulgur milling using roller, double disc and vertical disc mills, Journal of Food Engineering, vol.79(1), 2014, pp.181-187.

[16] Мельников С.В., Алешкин В.Р., Рощин П.М. Планирование эксперимента в исследованиях сельскохозяйственных процессов. (Experiment planning in agricultural process research). Ленинград: Колос, 1980, 168 р.

[17] Burdo O., Bandura V., Kolianovska L., Dukulis I. Experimental research of oil extraction from canola by using microwave technology. Engineering for Rural Development, Vol. 16, 2017, pp. 296-302.

[18] Rosenkranz S., Breitung-Faes S., Kwade A. Experimental investigations and modelling of the ball motion in planetary ball mills. Powder Technology, 212 (1), 2011, pp. 224-230.

[19] Johnson N., Lyon F. Statistics and Experiment Design in Engineering and Science: Experiment Design Methods, 1981, 520 p. 